\title{
Event-related potential correlates of interference effects on recognition memory
}

\author{
KenNeTh A. Norman \\ Princeton University, Princeton, New Jersey \\ AND \\ Katharine Tepe, Erika Nyhus, and Tim Curran \\ University of Colorado, Boulder, Colorado
}

\begin{abstract}
The question of interference (how new learning affects previously acquired knowledge and vice versa) is a central theoretical issue in episodic memory research, but very few human neuroimaging studies have addressed this question. Here, we used event-related potentials (ERPs) to test the predictions of the complementary learning systems (CLS) model regarding how list strength manipulations (strengthening some, but not all, items on a study list) affect recognition memory. Our analysis focused on the FN400 old-new effect, a hypothesized ERP correlate of familiarity-based recognition, and the parietal old-new effect, a hypothesized ERP correlate of recollection-based recognition. As is predicted by the CLS model, increasing list strength selectively reduced the ERP correlate of recollection-based discrimination, leaving the ERP correlate of familiarity-based discrimination intact. In a second experiment, we obtained converging evidence for the CLS model's predictions, using a remember/know test: Increasing list strength reduced recollection-based discrimination but did not reduce familiarity-based discrimination.
\end{abstract}

The question of how memory traces interfere with one another is one of the most fundamental and controversial topics in memory research. There is widespread agreement among memory theorists that interference is a major determinant of forgetting, but there is disagreement regarding the mechanisms of interference (see Anderson, 2003, and Mensink \& Raaijmakers, 1988, for contrasting perspectives on this issue) and the circumstances in which interference effects will be obtained.

This theoretical controversy has been fed by conflicting empirical results. For example, Ratcliff, Clark, and Shiffrin (1990) examined how list strength manipulations affect recognition memory: Is there a cost associated with memory strengthening, whereby strengthening memory for some list items impairs recognition of other (nonstrengthened) list items? Ratcliff et al. found that increasing list strength had no effect on the recognition of nonstrengthened items (i.e., participants' ability to discriminate between nonstrengthened items and lures was unimpaired). This finding has been replicated several times (see Norman, 2002, for a review). However, more recently, Norman (2002) showed that it is possible to observe a list strength effect (LSE) for recognition sensitivity in certain circumstances (e.g., when participants have to discriminate between studied words and switchedplurality distractors; Curran, 2000).

Computational models provide one possible approach toward reconciling these empirical conflicts. One such model is the complementary learning systems (CLS) neural network model of recognition memory, developed by Norman and O'Reilly (2003). This model presents a dual-process account of the LSE, whereby list strength manipulations should adversely affect recognition discrimination based on recollection of specific details (e.g., word plurality), but not discrimination based on nonspecific feelings of familiarity (for a related model, see Diana $\&$ Reder, 2005). The CLS model predicts a null LSE for familiarity-based discrimination because increasing list strength reduces the familiarity of both (nonstrengthened) studied items and lures; as such, the difference between studied item and lure familiarity does not change. There is an LSE for recollection-based discrimination because increasing list strength reduces studied item recollection and lure recollection is at floor (so the difference between studied item and lure recollection decreases).

The goal of the present study was to use event-related potentials (ERPs) to obtain converging evidence for the CLS model's predictions regarding interference effects on familiarity and recollection. In prior work, Curran (2000) and others have isolated two ERP effects - the FN400 old-new effect and the parietal old-new effect - that appear to index familiarity and recollection, respectively (for reviews, see Curran, Tepe, \& Piatt, 2006; Mecklinger, 2000; Rugg \& Curran, 2007; Wilding \& Sharpe, 2003; for an alternative account of the FN400, see Paller, Voss, \& Boehm, 2007).

K.A. Norman, knorman@princeton.edu 
The predictions of the CLS model regarding interference and ERPs are clear: Increasing list strength should reduce the ERP correlate of recollection (the parietal oldnew effect), but the ERP correlate of familiarity-based discrimination (the FN400 old-new effect) should be unaffected. Experiment 1 was designed to test this prediction.

\section{EXPERIMENT 1}

\section{Method}

\section{Participants}

Thirty-four University of Colorado students ( 8 of them female; mean age, 20.2 years) participated in the experiment for payment or course credit.

\section{Stimuli}

The stimuli were grayscale frontal view faces on a white background, created using a commercially available graphics package designed for recreating realistic faces of criminal suspects (Faces, the Ultimate Composite Picture, by Interquest, Washington, D.C.). Six categories of faces were created, with 53 faces in each category: African-American men, balding men, bearded men, long-haired women, narrow-faced men with glasses, and short-haired women with glasses (see Figure 1). The faces were about $6.5-7.5 \mathrm{~cm}$ high and $4.2-5.6 \mathrm{~cm}$ wide and were viewed from a distance of approximately $108 \mathrm{~cm}$.

\section{Design}

Memory status (old or new) and interference (strong or weak) were manipulated within participants. Memory status was varied within each of six study-test blocks, whereas interference was manipulated between blocks (three strong and three weak). Assignment of strongweak conditions to odd-even blocks was counterbalanced across participants. Each of the six face categories was assigned to a different block; this assignment was counterbalanced across participants. Within each category, two 20 -face sets were assigned in a counterbalanced fashion to the old-item and new-item conditions, and a third, 13-face set was used for primacy buffers and interference items.

\section{Procedure}

Each 2-h session began with a practice block with a seventh category of Asian men (10 studied and 20 tested faces) to acquaint the participants with the instructions and procedures. After application of the Geodesic Sensor Net (Tucker, 1993), each participant completed the six study-test blocks.

In each study phase, the participants studied 3 faces as primacy buffers (not on the later recognition test), followed by 20 target faces each presented three times (later tested), followed by 10 retroactive interference faces (not tested). Buffers, targets, and interference faces were not differentiated from the participants' perspective. Across the 60 target presentations, each of the 20 individual faces was presented once in each third of the target list in different random orders. In the weak interference condition, each interfering face was presented only once. In the strong interference condition, each interfering face was presented six times. Across the 60 strong interference presentations, each of the 10 individual faces was presented once in each sixth of the interference list in different random orders. During each study trial, the participants first saw a central plus sign for $500 \mathrm{msec}$, followed by a study face for $2,500 \mathrm{msec}$. The participants were instructed to determine whether the face was more happy or angry. Using the first two fingers of their right hand, the participants pressed either the 1 or the 2 key on a response box, corresponding to their judgment. The response key assignment was counterbalanced between participants. The participants made their judgment while viewing the face; if they did not respond in time, the monitor displayed "please respond more quickly."

Between the study and the test phases of the experiment, the participants played a computer game (Tetris). The length of the Tetris phase was complementary to the length of the study phase (strong interference Tetris length $=1 \mathrm{~min}$; weak interference Tetris length $=$ $3.5 \mathrm{~min}$ ). This adjustment ensured that the average time elapsed between studying a target face and being tested on that face was the same in the strong interference and the weak interference conditions.

In each test phase, the 20 studied target faces were randomly intermixed with 20 new faces. The last three interference items (from the study list) were presented at the end of the test list but were not scored; the purpose of testing interference items was to reinforce the idea that the participants should pay attention to interference items at study.
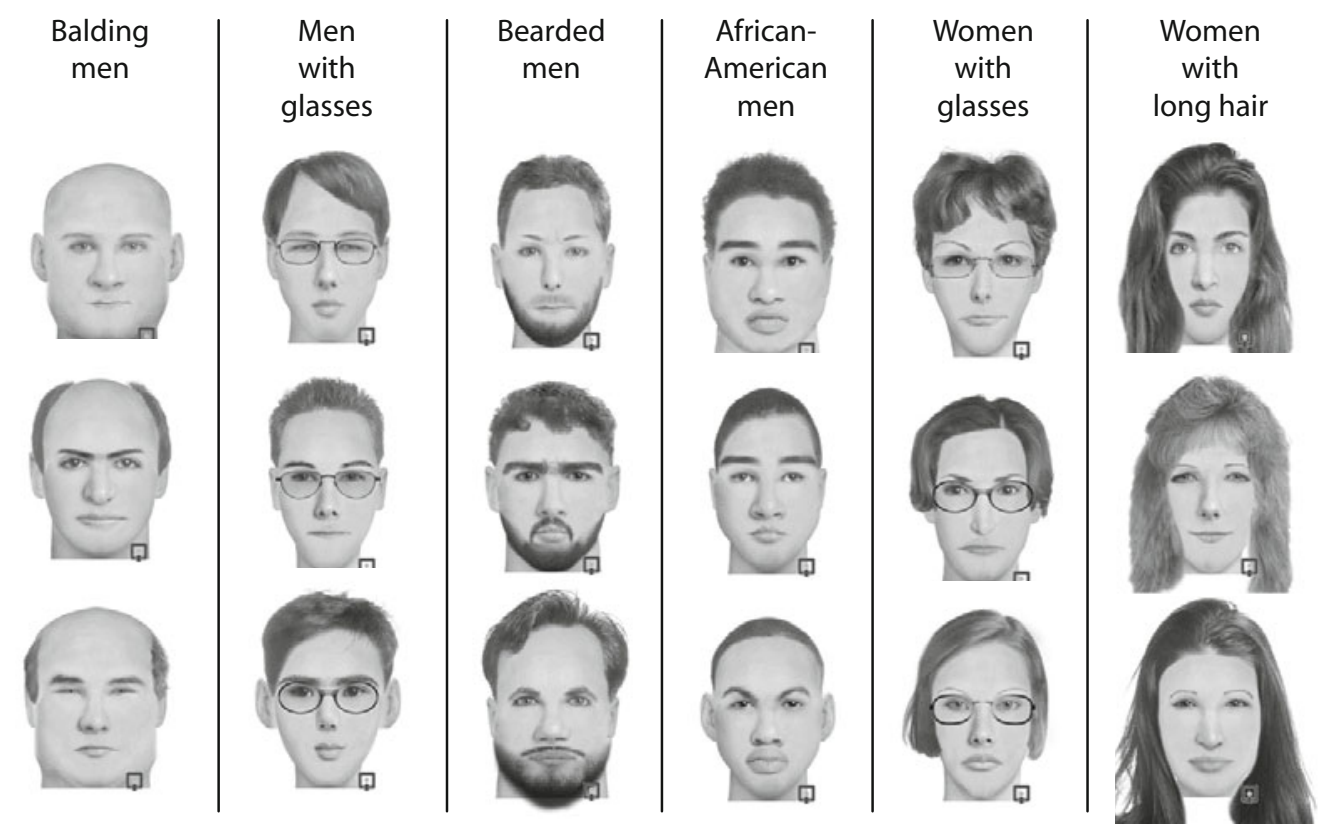

Figure 1. Representative stimuli from six face categories. 
Table 1

Behavioral Data From Experiment 1

\begin{tabular}{|c|c|c|c|c|c|c|c|c|}
\hline \multirow[b]{2}{*}{ Condition } & \multicolumn{2}{|c|}{ Hits } & \multicolumn{2}{|c|}{ False Alarms } & \multicolumn{2}{|c|}{$d^{\prime}$} & \multicolumn{2}{|c|}{$c$} \\
\hline & $M$ & $S E M$ & $M$ & $S E M$ & $M$ & $S E M$ & $M$ & $S E M$ \\
\hline Weak interference & .79 & .02 & .23 & .02 & 1.72 & .10 & -.06 & .07 \\
\hline Strong interference & .66 & .02 & .18 & .02 & 1.46 & .09 & .27 & .06 \\
\hline
\end{tabular}

Each trial started with a fixation circle that was roughly the same size as the faces $(7.1-\mathrm{cm}$ diameter) and that was presented for a randomly determined duration between 500 and $1,000 \mathrm{msec}$. Next, the test face was presented for $2,000 \mathrm{msec}$, and the participants were asked to withhold their old-new judgment until the face was replaced by a question mark $(4.2 \times 2.1 \mathrm{~cm})$. Once the question mark had appeared, the participants were asked to respond yes if the item was old and $n o$ if the item was new. After the participants had entered their response, the question mark was replaced by an open square (7.1-cm sides). Error messages were displayed for early responses prior to the question mark at $2 \mathrm{sec}$ or if a response was not detected within $10 \mathrm{sec}$. Either the square or an error message was displayed for $1 \mathrm{sec}$ prior to initiation of the next trial. Response key assignment was counterbalanced across participants.

\section{EEG/ERP Recording and Analysis}

During the test phase, scalp voltages were collected with a 128-channel Geodesic Sensor Net (Tucker, 1993) connected to an ACcoupled, 128-channel, high-input impedance amplifier (200 M $\Omega$; Net Amps, Electrical Geodesics, Eugene, OR). Amplified analog voltages ( 0.1 to $100-\mathrm{Hz}$ band-pass) were digitized at $250 \mathrm{~Hz}$. Individual sensors were adjusted until impedances were less than $50 \mathrm{k} \Omega$. The EEG was digitally low-pass filtered at $40 \mathrm{~Hz}$. Eye movements were corrected using an ocular artifact correction algorithm (Gratton, Coles, \& Donchin, 1983). Individual bad channels were replaced on a trial-by-trial basis with a spherical spline algorithm, but trials were discarded if more than $20 \%$ of the channels were bad (average amplitude over $100 \mu \mathrm{V}$ or transit amplitude over $50 \mu \mathrm{V}$ ). EEG was measured with respect to a vertex reference $(\mathrm{Cz})$, but an average-reference transformation was used to minimize the effects of reference site activity and accurately estimate the scalp topography of the measured electrical fields. The average reference was corrected for the polar average-reference effect (Junghöfer, Elbert, Tucker, \& Braun, 1999). The number of trials/participant/condition used to calculate ERPs were as follows: strong/new $(M=46$, range $=34-58)$, strong $/$ old $(M=38$, range $=22-52)$, weak $/$ new $(M=$ 44 , range $=27-56)$, and weak/old $(M=45$, range $=27-57)$.

\section{Results}

\section{Behavioral Results}

Table 1 shows the behavioral results from Experiment $1 .{ }^{1}$ We computed standard signal detection measures of sensitivity and bias $\left(d^{\prime}\right.$ and $\left.c\right)$. According to these measures, increasing list strength reduced recognition sensitivity $\left[t(33)=3.18, p<.01, \eta^{2}=.23\right]$. Also, the participants responded more conservatively in the strong interference condition $\left[t(33)=6.83, p<.01, \eta^{2}=.59\right]$; this is a common finding in list strength studies (see, e.g., Hirshman, 1995).

\section{ERP Results}

Spatiotemporal regions of interest (ROIs) were defined according to previous research for both the FN400 and the parietal old-new effects (Curran, 2000; Curran, DeBuse, Woroch, \& Hirshman, 2006). For FN400 old-new effects, ROIs were the left and right anterior, superior channel groups (LAS and RAS, shown in Figure 2); mean amplitude from 300 to $500 \mathrm{msec}$ was computed by averaging the channels within each region for each condition/ participant. For parietal old-new effects, ROIs were the left and right posterior, superior channel groups (LPS and RPS, shown in Figure 2); mean amplitude from 400 to $800 \mathrm{msec}$ was computed by averaging the channels within each region for each condition/participant. Mean FN400 and parietal ERP amplitude values are shown in Figure 3. Average waveforms are shown in Figure 4, and topographic plots of the ERP effects are shown in Figure 5.

Mean amplitudes for Experiment 1 were analyzed with a strength (strong or weak) $\times$ old/new $\times$ hemisphere ANOVA. Table 2 reports the results of these analyses. Hemisphere effects did not interact with other factors of interest and, thus, are not reported in Table 2.

FN400 old-new effects. Amplitudes were more positive for old than for new faces, but list strength did not affect amplitudes (see Figure 3A and Table 2). Pairwise comparisons indicate that the old-new differences were significant for both the weak interference condition $[F(1,33)=4.72$, $\left.p=.04, \eta^{2}=.13\right]$ and the strong interference condition $\left[F(1,33)=4.60, p=.04, \eta^{2}=.12\right]$.

Parietal old-new effects. There was an interaction between list strength and old-new effects, so that, as was

Table 2

Statistics Computed on the Basis of Mean Amplitudes of FN400 and Parietal ERP Effects, Showing Effects of Interference (List Strength) and Study Status (Old vs. New)

\begin{tabular}{|c|c|c|c|c|c|}
\hline Time Period & Region & Effect & $F$ & $p$ & $\eta^{2}$ \\
\hline \multirow[t]{3}{*}{$300-500 \mathrm{msec}$} & LAS and RAS ROIs & Strength & 0.019 & .89 & .001 \\
\hline & (FN400 effect) & Old/new & 5.27 & .03 & .14 \\
\hline & & $\begin{array}{l}\text { Strength } \times \\
\text { old } / \text { new }\end{array}$ & 0.0004 & .98 & .00001 \\
\hline \multirow[t]{3}{*}{$400-800 \mathrm{msec}$} & LPS and RPS ROIs & Strength & 0.06 & .80 & .002 \\
\hline & (parietal effect) & Old/new & 1.14 & .29 & .03 \\
\hline & & $\begin{array}{l}\text { Strength } \times \\
\text { old/new }\end{array}$ & 5.58 & .02 & .14 \\
\hline
\end{tabular}

Note-See Figure 3 for mean amplitude values. L, left; R, right; A, anterior; P, posterior; S, superior. 


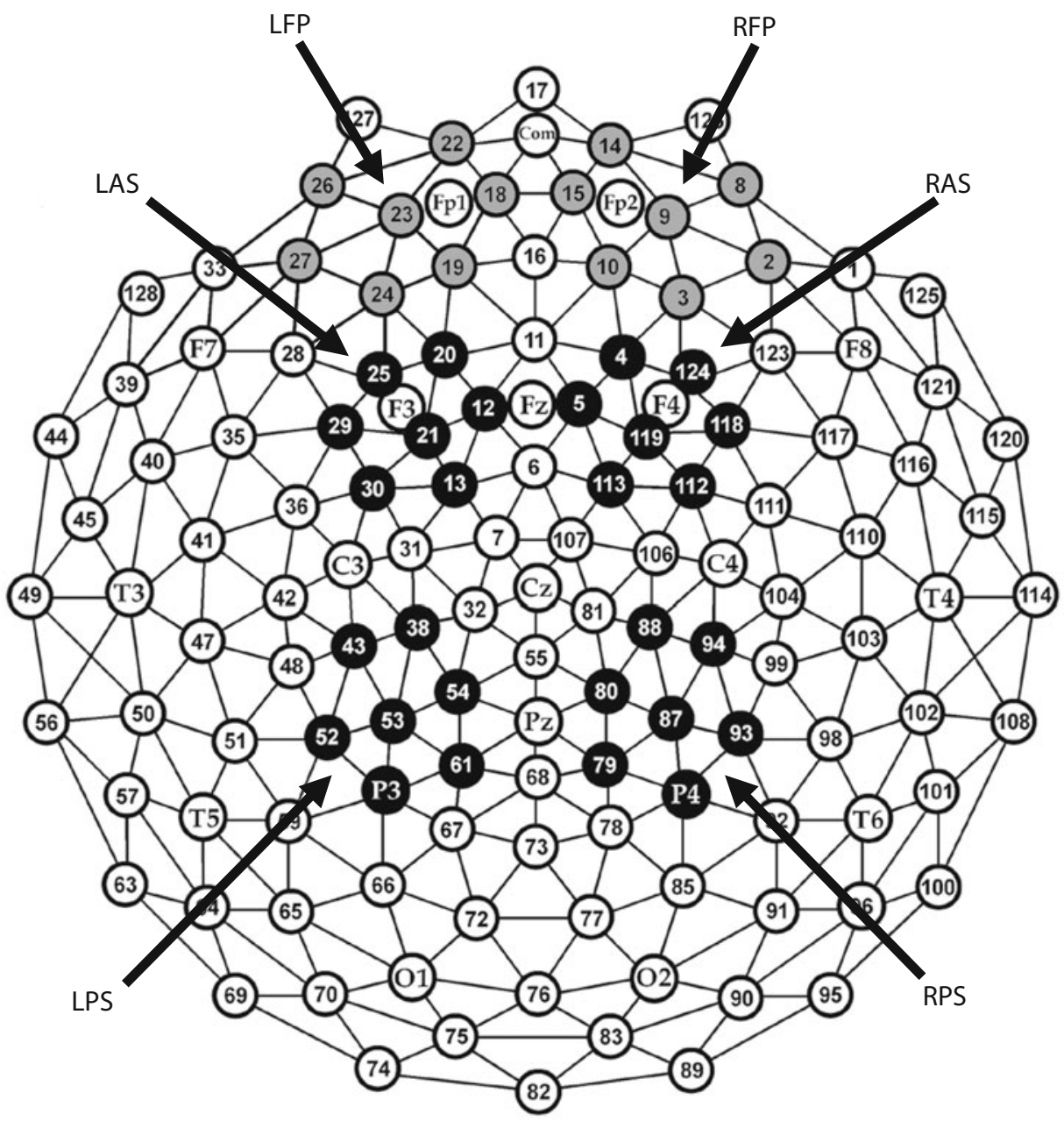

Figure 2. Geodesic Sensor Net layout. Electrode sites are numbered, along with selected 10-10 positions. Black clusters are regions of interest included in the analyses. L, left; R, right; $A$, anterior; P, posterior; S, superior, FP, fronto-polar.

FN400

A $\quad(300-500 \mathrm{msec})$

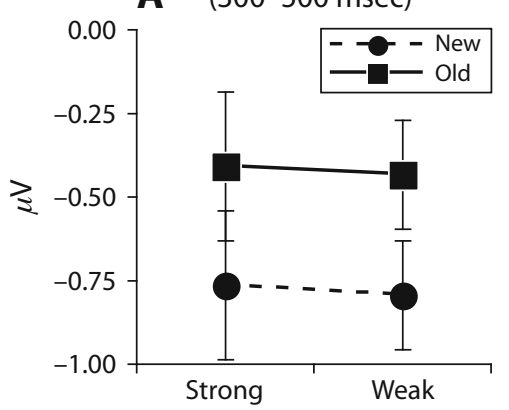

Parietal

B $(400-800 \mathrm{msec})$

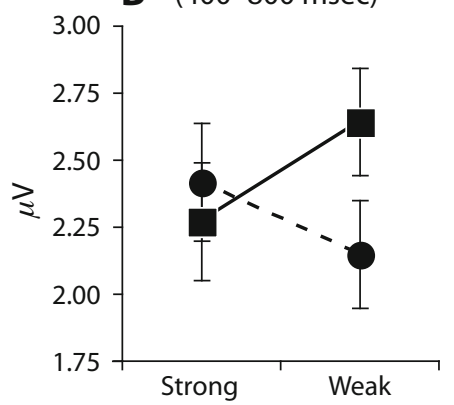

Figure 3. Mean amplitudes for the FN400 ERP (left and right anterior, superior regions, $300-500 \mathrm{msec}$ ) and the parietal ERP (left and right posterior, superior regions, $\mathbf{4 0 0 - 8 0 0 ~} \mathbf{m s e c}$ ) as a function of list strength and study status. Error bars indicate the standard errors of the old-new difference. (A) Effect of list strength on FN400 ERP amplitude. (B) Effect of list strength on parietal ERP amplitude. 


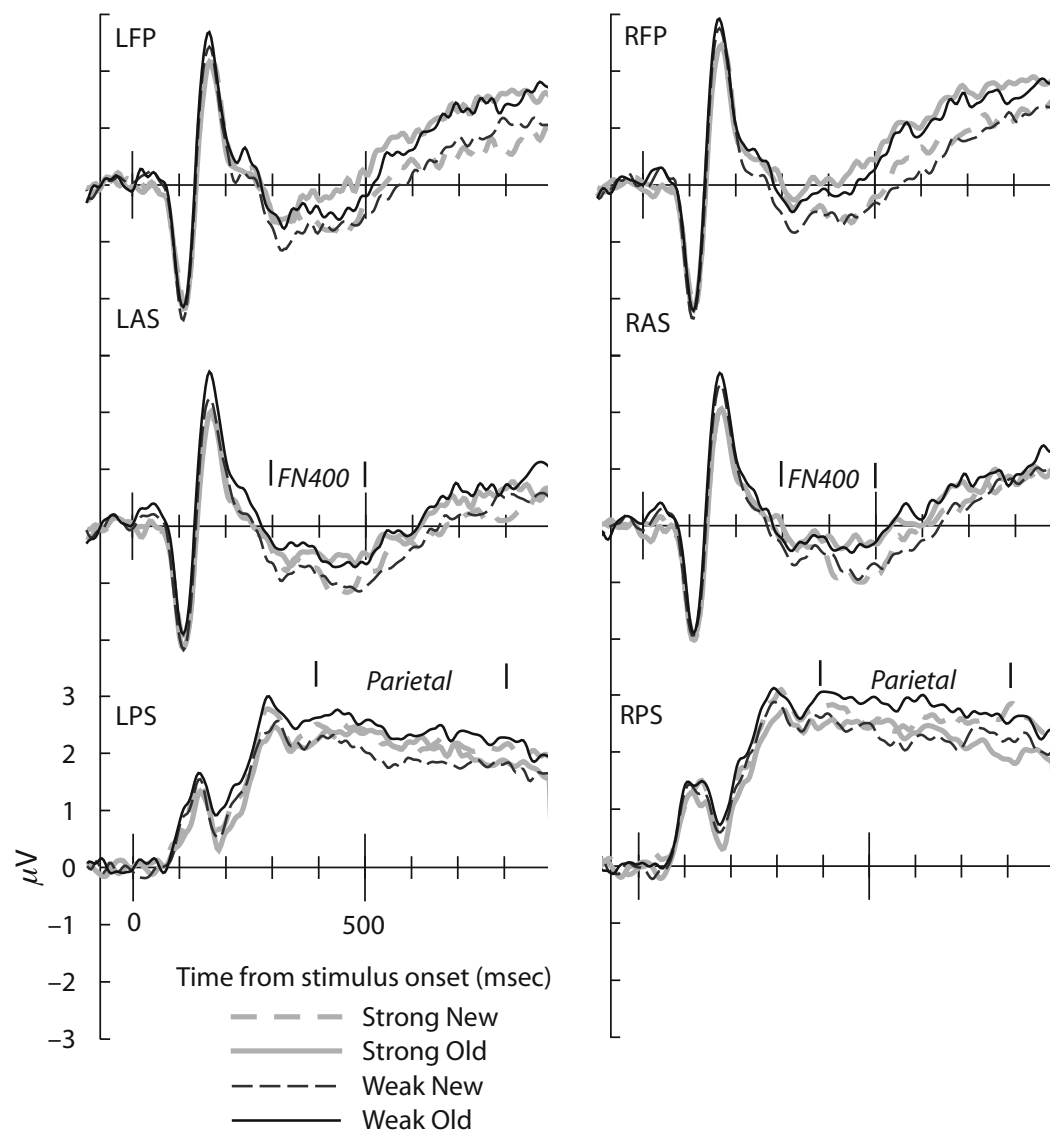

Figure 4. Average ERP waveforms for the six regions shown in Figure 2. Time points used to compute the FN400 and parietal ERP effects are marked on the figure. $\mathrm{L}$, left; $\mathrm{R}$, right; A, anterior; $\mathrm{P}$, posterior; $\mathrm{S}$, superior; FP, fronto-polar.

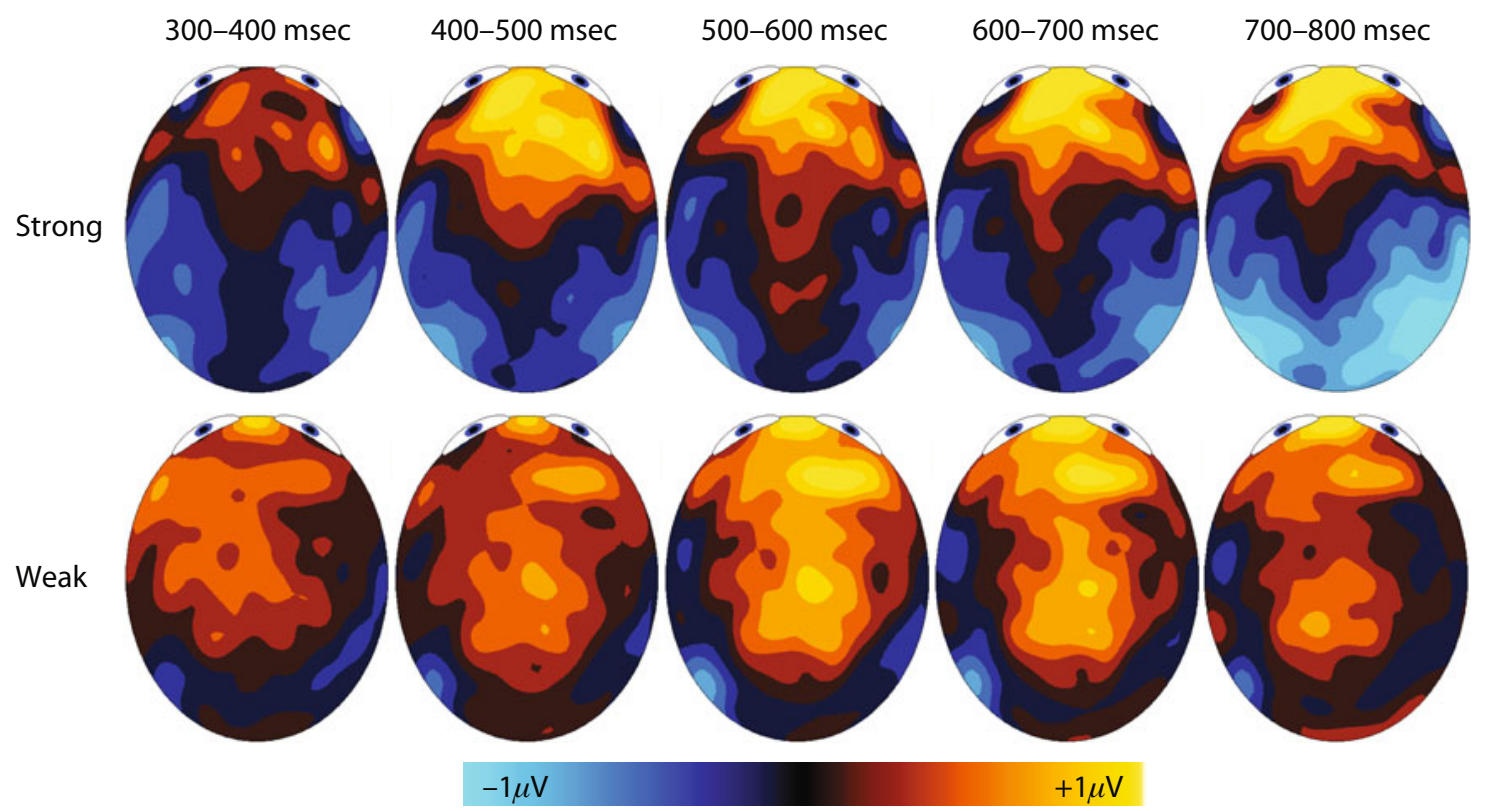

Figure 5. Topographic plots of old-new differences for the strong interference condition (top row) and the weak interference condition (bottom row) from 300 to $800 \mathrm{msec}$ in 100-msec intervals. Blue indicates more negative and red indicates more positive, ranging from to -1 to $+1 \mu \mathrm{V}$. 
predicted, the difference between old and new faces was greater in the weak interference condition than in the strong interference condition (see Figure 3B and Table 2). Pairwise comparisons indicate that the old-new difference was significant for the weak interference condition $[F(1,33)=$ $\left.6.66, p=.01, \eta^{2}=.17\right]$; the old-new difference was nonsignificant (and numerically reversed: new $>$ old) in the strong interference condition $\left[F(1,33)<1, \eta^{2}=.02\right]$.

Fronto-polar old-new effects. Figure 5 shows scalp topographies for the old-new effect from 300 to $800 \mathrm{msec}$ for the strong interference and weak interference conditions. In addition to the FN400 and parietal effects, these topographies show a sustained frontal old-new effect extending beyond the $300-$ to $500-\mathrm{msec}$ window of the FN400 (for a review of similar effects, see Mecklinger, 2000; Wilding \& Sharpe, 2003). We examined two electrode clusters surrounding standard fronto-polar locations Fp1 and Fp2 at 100-msec intervals from 300 to $800 \mathrm{msec}$ (LFP and RFP; see Figure 2). Results from this analysis showed a significant old-new difference starting at $400 \mathrm{msec}$ (all $p \mathrm{~s} \leq .01)$ that never approached a significant interaction with hemisphere or strength.

\section{Discussion}

The ERP findings from Experiment 1 provide support for the CLS model's prediction that list strength affects recollection-based discrimination, but not familiaritybased discrimination. However, as was noted by Poldrack (2006), reverse inferences of this sort (i.e., inferring properties of cognitive processes on the basis of neural data) are debatable in the absence of converging evidence. To obtain further support of the model's list strength predictions, we ran a behavioral version of Experiment 1 where we collected data on recollection and familiarity using a remember-know test (Tulving, 1985). Specifically, for items recognized as being old, the participants were asked whether they remember the item (i.e., recollect specific details from the study phase) or whether it just seems $f a$ miliar (but no specific details come to mind).

Although it is clear that remember and familiar responses are not completely pure estimates of recollection and familiarity (see, e.g., Wixted \& Stretch, 2004), estimates of recollection and familiarity derived from self-report data converge strongly with other measures of recollection and familiarity that do not rely on self-report data (see Yonelinas, 2002, for a review of relevant findings). In keeping with the predictions of the CLS model and the ERP results from Experiment 1, we expected that increasing list strength would selectively affect estimates of recollection-based discrimination, leaving estimates of familiarity-based discrimination intact.

\section{EXPERIMENT 2}

Method
Participants
Twenty-four University of Colorado students (17 of them female;
mean age, 18.9 years) participated in the experiment for payment or
course credit.

\section{Stimuli, Design, and Procedure}

Experiment 2 was identical to Experiment 1, except that we did not collectEEG data and we collected remember-familiardata at test. At the start of the experiment, we gave the participants standard rememberfamiliar instructions that explained the difference between recollection of specific details versus nonspecific feelings of familiarity (see, e.g., Norman, 2002; Rajaram, 1993). The participants were then told to respond remember at test if they specifically recollected anything they experienced while making the happy-angry judgment for the face (i.e., they remembered some thought or reaction that they had when making the happy-angry judgment) and to respond familiar if the item seemed familiar but they did not specifically recollect details pertaining to the happy-angry judgment. During the test phase, after each test stimulus had been presented, a question mark appeared. The participants were instructed to first give a yes-no response indicating whether they thought the item was old (yes) or new (no). Next, if the participants responded yes, they were asked to indicate whether they remembered the item or whether it just seemed familiar.

To compute process-specific estimates of sensitivity based on remember-familiar data, we used the independence rememberknow procedure outlined by Jacoby, Yonelinas, and Jennings (1997). Assuming that recollection and familiarity are independent, the overall probability of responding old on the basis of familiarity $=$ the probability of responding old to nonrecollected items on the basis of familiarity $=F /(1-R)$. In this formula, $F=$ the probability of making a familiar response; and $R=$ the probability of making a remember response. To compute familiarity-based sensitivity, we applied the $d^{\prime}$ formula to familiarity-based hit and false alarm rates; we call this measure $F d^{\prime}$. To compute recollection-based sensitivity, we computed $P(\mathrm{R})=($ remember hits - remember false alarms $) /$ $(1-$ remember false alarms).

\section{Results}

Table 3 shows the raw behavioral results from Experiment 2 (proportions of old, remember, and familiar responses, where old $=$ remember + familiar), and Table 4 shows derived measures of sensitivity.

The most important predictions of the CLS model relate to process-specific estimates of sensitivity: List strength should affect recollection-based sensitivity, but not familiarity-based sensitivity. Both of these predictions were confirmed: Increasing list strength led to a significant decrease in $P(\mathrm{R})\left[t(23)=5.27, p<.0001, \eta^{2}=.55\right.$; two-tailed]. However, increasing list strength did not lead to a decrease in $F d^{\prime}\left[t(23)=1.19, p=.25, \eta^{2}=.06\right.$; twotailed]. ${ }^{2}$ Note that our use of $P(\mathrm{R})$ assumes that recollection is a high-threshold process, but our findings do not depend on this assumption; other single-point estimates of sensitivity (e.g., $d^{\prime}$ computed on remember responses) yield exactly the same pattern of results.

As in Experiment 1, overall recognition sensitivity was indexed by computing $d^{\prime}$ on the basis of old responses to

Table 3

Behavioral Data (Old, Remember, and Familiar Responses) From Experiment 2

\begin{tabular}{|c|c|c|c|c|c|c|c|}
\hline \multirow[b]{2}{*}{ Condition } & \multirow{2}{*}{$\begin{array}{l}\text { Item } \\
\text { Type }\end{array}$} & \multicolumn{2}{|c|}{ Old } & \multicolumn{2}{|c|}{ Remember } & \multicolumn{2}{|c|}{ Familiar } \\
\hline & & $M$ & SEM & $M$ & SEM & $M$ & $S E M$ \\
\hline \multirow[t]{2}{*}{ Weak interference } & Target & .67 & .04 & .40 & .04 & .28 & .03 \\
\hline & Lure & .21 & .03 & .04 & .01 & .17 & .03 \\
\hline \multirow[t]{2}{*}{ Strong interference } & Target & .60 & .03 & .29 & .03 & .31 & .03 \\
\hline & Lure & .17 & .04 & .05 & .02 & .13 & .03 \\
\hline
\end{tabular}


Table 4

Derived Measures of Recognition Sensitivity From Experiment 2

\begin{tabular}{|c|c|c|c|c|c|c|}
\hline \multirow[b]{2}{*}{ Condition } & \multicolumn{2}{|c|}{$d^{\prime}(\mathrm{Old})$} & \multicolumn{2}{|c|}{$P(\mathrm{R})$} & \multicolumn{2}{|c|}{$F d^{\prime}$} \\
\hline & $M$ & SEM & $M$ & SEM & $M$ & SEM \\
\hline Weak interference & 1.48 & 0.10 & .37 & .04 & 1.00 & 0.10 \\
\hline Strong interference & 1.43 & 0.10 & .26 & .02 & 1.12 & 0.10 \\
\hline
\end{tabular}

studied items and lures; we call this measure $d^{\prime}(\mathrm{Old})$. Unlike Experiment 1 (where we found a significant LSE for overall sensitivity), the effect of list strength on $d^{\prime}(\mathrm{Old})$ was not significant in this experiment $[t(23)=0.45, p=$ $.66, \eta^{2}=.01$; two-tailed]. One possible explanation of this result is that remember-familiar instructions in Experiment 2 may have encouraged the participants to pay more attention to familiarity (relative to recollection) when making their old-new recognition decisions, thereby reducing the overall LSE.

\section{GENERAL DISCUSSION}

Taken together, the ERP results presented in Experiment 1 and the remember-familiar results presented in Experiment 2 provide strong support for the CLS model's predictions about list strength effects. In Experiment 1, list strength reduced the hypothesized ERP correlate of recollection-based discrimination (the parietal old-new effect) but did not affect the hypothesized ERP correlate of familiarity-based discrimination (the FN400 old-new effect). In Experiment 2, list strength reduced discrimination based on self-report measures of recollection but did not reduce discrimination based on self-report measures of familiarity.

In most cases, including the present Experiment 2, remember-familiar results are consistent with a singleprocess model whereby remember and familiar responses merely reflect more and less conservative response criteria, respectively, placed along a single memory strength axis (e.g., Dunn, 2004). Although the single-process alternative is sometimes favored as being more parsimonious, the present combination of ERP results from Experiment 1 and remember-familiar results from Experiment 2 is better explained by the dual-process view. Although remember-familiar results can often be explained using a single underlying process, there is no way to interpret the parietal and FN400 ERP effects as reflecting highversus low-confidence responses along a single strength axis. Parietal effects are associated primarily with highconfidence hits (as would be expected of a recollection process; see Yonelinas, 2002), but FN400 old-new differences are observed for both high- and low-confidence responses (Azimian-Faridani \& Wilding, 2006; Curran, 2004; Rubin, Van Petten, Glisky, \& Newberg, 1999; Woodruff, Hayama, \& Rugg, 2006).

This is not the first study to show that list strength affects recollection-based recognition, but not familiaritybased recognition. As was mentioned in the introduction, Norman (2002, Experiment 2) found a robust LSE for rec- ognition sensitivity on a plurality memory test where subjects had to recollect whether they had studied the singular or the plural form of a word; when distractors were less similar to studied items (and, consequently, demands on recollection were less strong), the LSE was not significant. Also, Norman (2002, Experiment 1) collected rememberfamiliar data in a list strength experiment using word stimuli; a subsequent reanalysis of the remember-familiar data (published in Norman \& O'Reilly, 2003) showed that list strength significantly reduced recollection-based discrimination but did not affect familiarity-based discrimination. Experiment 2 of the present study replicates this overall pattern of results and extends it to the domain of novel face stimuli.

\section{CONCLUSIONS}

This study shows that ERP methods can serve as a source of converging evidence to bring to bear on computational accounts of interference. Specifically, the present ERP results (coupled with the remember-familiar data from Experiment 2) suggest that increasing list strength diminishes recollection-based recognition performance, but not familiarity-based recognition performance, as is predicted by the CLS model (Norman \& O'Reilly, 2003). More generally, the results of this study show that interference manipulations can have a powerful effect on the neural correlates of memory and, thus, are worthy of scrutiny in future neuroimaging research.

\section{AUTHOR NOTE}

This work was supported by NIH Grant MH64812. We thank Cathy Anderson, Dan Collins, Kristal Moller, Carley Piatt, and Brion Woroch for help with participant testing and stimulus creation. Correspondence concerning this article should be addressed to K. A. Norman, Department of Psychology, Princeton University, Green Hall, Washington Rd., Princeton, NJ 08540 (e-mail: knorman@princeton.edu).

\section{REFERENCES}

Anderson, M. C. (2003). Rethinking interference theory: Executive control and the mechanisms of forgetting. Journal of Memory \& Language, 49, 415-445.

AZIMIAN-FARIDANI, N., \& WILDING, E. L. (2006). The influence of criterion shifts on electrophysiological correlates of recognition memory. Journal of Cognitive Neuroscience, 18, 1075-1086.

Curran, T. (2000). Brain potentials of recollection and familiarity. Memory \& Cognition, 28, 923-938.

Curran, T. (2004). Effects of attention and confidence on the hypothesized ERP correlates of recollection and familiarity. Neuropsychologia, 42, 1088-1106.

Curran, T., DeBuse, C., Woroch, B., \& Hirshman, E. (2006). Combined pharmacological and electrophysiological dissociation of familiarity and recollection. Journal of Neuroscience, 26, 1979-1985.

Curran, T., Tepe, K. L., \& Piatt, C. (2006). ERP explorations of dual processes in recognition memory. In H. D. Zimmer, A. Mecklinger, \& U. Lindenberger (Eds.), Binding in human memory: A neurocognitive approach (pp. 467-492). Oxford: Oxford University Press.

Diana, R. A., \& Reder, L. M. (2005). The list strength effect: A contextual competition account. Memory \& Cognition, 33, 1289-1302.

Dunn, J. C. (2004). Remember-know: A matter of confidence. Psychological Review, 111, 524-542.

Gratton, G., Coles, M. G., \& Donchin, E. (1983). A new method for off-line removal of ocular artifact. Electroencephalography \& Clinical Neurophysiology, 55, 468-484. 
Hirshman, E. (1995). Decision processes in recognition memory: Criterion shifts and the list-strength paradigm. Journal of Experimental Psychology: Learning, Memory, \& Cognition, 21, 302-313.

Jacoby, L. L., Yonelinas, A. P., \& Jennings, J. M. (1997). The relation between conscious and unconscious (automatic) influences: A declaration of independence. In J. D. Cohen \& J. W. Schooler (Eds.), Scientific approaches to consciousness (pp. 13-47). Mahwah, NJ: Erlbaum.

Junghöfer, M., Elbert, T., Tucker, D. M., \& Braun, C. (1999). The polar average reference effect: A bias in estimating the head surface integral in EEG recording. Clinical Neurophysiology, 110, 1149-1155.

Macmillan, N. A., \& Creelman, C. D. (1991). Detection theory: A user's guide. New York: Cambridge University Press.

Mecklinger, A. (2000). Interfacing mind and brain: A neurocognitive model of recognition memory. Psychophysiology, 37, 565-582.

Mensink, G., \& RaAimakers, J. G. (1988). A model for interference and forgetting. Psychological Review, 95, 434-455.

Norman, K. A. (2002). Differential effects of list strength on recollection and familiarity. Journal of Experimental Psychology: Learning, Memory, \& Cognition, 28, 1083-1094.

Norman, K. A., \& O'Reilly, R. C. (2003). Modeling hippocampal and neocortical contributions to recognition memory: A complementarylearning-systems approach. Psychological Review, 104, 611-646.

Paller, K. A., Voss, J. L., \& Boehm, S. G. (2007). Validating neural correlates of familiarity. Trends in Cognitive Sciences, 11, 243-250.

Poldrack, R. A. (2006). Can cognitive processes be inferred from neuroimaging data? Trends in Cognitive Sciences, 10, 59-63.

RAJARAM, S. (1993). Remembering and knowing: Two means of access to the personal past. Memory \& Cognition, 21, 89-102.

Ratcliff, R., Clark, S. E., \& Shiffrin, R. (1990). The list strength effect: I. Data and discussion. Journal of Experimental Psychology: Learning, Memory, \& Cognition, 16, 163-178.

Rubin, S. R., Van Petten, C., Glisky, E. L., \& Newberg, W. M. (1999). Memory conjunction errors in younger and older adults: Event-related potential and neuropsychological data. Cognitive Neuropsychology, 16, 459-488.

RugG, M. D., \& Curran, T. (2007). Event-related potentials and recognition memory. Trends in Cognitive Sciences, 11, 251-257.

TucKer, D. M. (1993). Spatial sampling of head electrical fields: The geodesic sensor net. Electroencephalography \& Clinical Neurophysiology, 87, 154-163.

Tulving, E. (1985). Memory and consciousness. Canadian Psychology, 26, 1-12.

WiLDING, E. L., \& ShaRpe, H. (2003). Episodic memory encoding and retrieval: Recent insights from event-related potentials. In A. Zani \& A. M. Proverbio (Eds.), The cognitive electrophysiology of mind and brain (pp. 169-196). San Diego, CA: Academic Press.

WiXted, J. T., \& STRETCH, V. (2004). In defense of the signal detection interpretation of remember/know judgments. Psychonomic Bulletin \& Review, 11, 616-641.

Woodruff, C. C., Hayama, H. R., \& Rugg, M. D. (2006). Electrophysiological dissociation of the neural correlates of recollection and familiarity. Brain Research, 1100, 125-135.

Yonelinas, A. P. (2002). The nature of recollection and familiarity: A review of 30 years of research. Journal of Memory \& Language, 46, 441-517.

\section{NOTES}

1. We corrected for a hit rate of 1.0 in 1 participant in Experiment 1, using $1.0-.5 / n$ (Macmillan \& Creelman, 1991).

2. When computing $d^{\prime}(\mathrm{Old})$ and $F d^{\prime}$ in Experiment 2, we corrected for a false alarm rate of 0.0 in 1 participant by replacing this zero value with $.5 / n$ (Macmillan \& Creelman, 1991).

(Manuscript received July 24, 2006; revision accepted for publication July 6, 2007.) 